\title{
CORRESPONDENCE
}

\section{Creation in California}

Sir,-Your attitude to California's creationists is understandable. Unfortunately, it will help to perpetuate two popular fallacies which call for correction.

First, not all Bible-believers are like those referred to in the Californian textbook, who seem to think the Earth was created in six literal days, only a few thousand years ago. Such fundamentalists are right at one end of a long spectrum of belief. Others-probably a much larger number-accept the facts of geology, but think that the idea of many successive creative acts over the ages fits those facts better than the theory of natural evolution. Further along the spectrum still are a great number of theistic evolutionists, who think that some kind of evolution did occur but that natural selection alone cannot account for it: according to them, a liberal application of divine creative power must have been needed to make evolution work.

Secondly, there are more antiDarwinists in British universities than you seem to realize. Among them is a friend of mine who holds a chair in a department of pure science "in a field bearing on the evolutionary question", to use your phrase. If his friends ask why he keeps quiet about his unorthodox views, he replies in words very like those used recently in another connexion by Professor Ian Roxburgh :

"Science is only concerned with the truth, and as the way to truth is by conjecture and refutation, why don't they (orthodox scientists) listen? Science is not like that at all. There is a powerful establishment and a belief system. There are power seekers and career men, and if someone challenges the establishment he should not expect a sympathetic hearing."

The majority of biologists accept the prevailing views uncritically-just as a great many competent Russian biologists were once brainwashed into accepting Lysenko's quackery. Others have thought for themselves and come to realize the flaws in contemporary Darwinism. But for them to speak out would be to invite ridicule, and probably ruin their careers. Can you blame them for keeping silent? Do you really suppose that the offer of a year's free subscription to Nature will tempt them to expose themselves?

Only a man at the peak of his career could afford to do this, as W. R. Thompson once did. Shortly before he retired he was invited to write an intro- duction to a centenary edition of The Origin of Species. This eminent entomologist, whose recent obituary in Nature described his career as "long and distinguished" and his impact as likely to be "of lasting academic value", declined because he was no Darwinist. Eventually he was persuaded, and wrote a highly critical introduction in which he said :

"It does occur to me, in the first place, that Darwin in the Origin was not able to produce palaeontological evidence sufficient to prove his views, but that the evidence he did produce was adverse to them; and I may note that the position is not notably different today.

". . . This situation, where scientific men rally to the defence of a doctrine they are unable to define scientifically, much less demonstrate with scientific rigour, attempting to maintain its credit with the public by the suppression of criticism and the elimination of difficulties, is abnormal and undesirable in science. Thus are engendered those fragile towers of hypotheses based on hypotheses, where fact and fiction mingle in an inextricable confusion."3

These are not isolated remarks taken out of context. They truly represent Thompson's views. Anyone who thinks that only uninformed cranks reject Darwinism should read the whole of Thompson's Introduction. It will make him think again.

$$
\begin{aligned}
& \text { Yours faithfully, } \\
& \text { A. T. J. HAYWARD }
\end{aligned}
$$

2 Wellington Road,

East Kilbride,

Glasgow G75 8RB

1 New Scientist, September 28, 602 (1972).

2 Nature, 238, 116 (1972).

3 Everyman Library No. 811 (Dent, London, 1956).

\section{Objective Testing}

SIR,-May I answer Roy Cox (Nature, 237,189 ; 1972) on the advantages claimed for objective testing (OT) over the "essay" paper? I must stress that the so-called "essay" paper usually has some questions to which essay answers are necessary and also fragmented questions ("Write notes on:...", and so on) and often one or more problems.

After quarrelling with Dr Cox over several specific points, I should like then to deal with other points he did not mention.

(1) In the older type of OT, the answer is a word or phrase. Since there are no suggested answers to prompt the candidate, we may call this type "recall" OT (ROT). In the modern multiple choice or matching, the answer is suggested - "suggestive" OT (SOT). When it is desirable to expect a candidate to know not an exact answer but merely a range in which the answer may be, SOT can be useful, for example, that the Battle of Hastings was in 1066 rather than $55 \mathrm{BC}, 1492,1815$ or 1942. But this is the kind of SOT question for which it is most difficult to obtain other equally plausible suggested answers, or "distractors". In most cases, however, it seems to be used in preference to ROT either to allow mechanical marking or merely to be fashionable.

(2) The student can know what to expect just as easily in a well set essay paper as in an OT paper. How is a reappraisal of study objectives prompted more effectively by OT testing?

(3) The National Board of Medical Examiners compared OT and essay marks with something even more subjective than the latter-teacher opinion. Such a comparison is worthless.

In the work cited of Anderson, Dykes and Lennon, OT and essay marks were compared with the totals of both. Unfortunately, any unreliability in $X$ or $Y$ must be reflected in $X+Y$.

Two important advantages of OT are readier obtaining of spread and accuracy of marking.

(1) To be fair, a paper must cover the syllabus as widely and as evenly as possible. Although easier with a 50 - or a 100-question OT paper than with a 6- or 8-question essay paper, spread can be obtained in a carefully set essay paper-and an OT examiner can allow his enthusiasm for certain areas of work to lead to bad spread.

(2) The more subjective the answers, the more difficult the marking. Essays are necessarily more subjective than answers to fragmented questions or problems, and, of course, OT questions. But difficulties with essay papers are often exaggerated and can largely be overcome. Because of the number of questions in an essay paper and of papers in an examination, errors in the marking of essay questions will tend to cancel one another and the residual cumulative error is buffered by the greater accuracy in marking fragmented and problem questions. Use of a marking scheme can sharpen accuracy of marking and increase agreement among those marking the same material. The more specific the wording of the ques- 
tion, the less room there is for differences of opinion on what is wanted in the answer. Finally, I must stress that, although in OT ranking order is exact, there is still the question of where to put both the pass-fail and any inter-class barriers.

Certain disadvantages of OT should be mentioned.

(1) Setting can be as time-consuming as machine-marking is simple. Spread must continuously be checked; the position of the right answer must be varied; distractors must be both plausible and of similar plausibility. Finally, in the marking, there must be a penalty for guessing.

(2) Especially in SOT, there is only one right answer. Especially in science, a particular point may be very debatable and anything but simple. Like programmed learning (get the sole accepted answer before going on to the next step), OT can inject an unhealthy authoritarianism and superficiality.

(3) In general, both knowledge of facts and ability to apply them should be tested. Ability to choose relevant facts and marshall them in logical order can be tested only by the essay (or orally). Even if there is a problem in an OT paper, one can know only what answer has been derived (or, in SOT, selected). What is much more important, how this was deduced can never be known.

(4) At times OT can test even factual knowledge only in a very cumbersome manner if at all. The sensible test of a definition is to ask for it-which may be beyond the scope of an ROT question ; ability to translate (knowledge of vocabulary and grammar) can be tested only by translation; knowledge of phonetics is best tested by writing a passage in phonetics; one of the best tests of familiarity with literature is the question "Assign to context: ...."

(5) Such a question as "With an example for each consonant mentioned, give an account of Grimm's Law", although an essay question is not only about the only one that could be asked on the Law, but is also quite objective. All these examples are of areas in which the "essay" question is superior to the OT question in testing factual knowledge and can be marked as accurately as the latter.

OT is not to be condemned bell, book and candle. All methods of examining have their merits and demerits. Since Dr Cox's paper leaned heavily towards OT, it is only right that my reply should emphasize the opposite case.

Yours faithfully,

$$
\text { P. A. Ongley }
$$

Department of Chemistry,

University of Aston,

Gosta Green,

Birmingham B4 ET18

\section{Cancer Research}

SIR,-Dr John Paul comments (Nature, 240,$492 ; 1972$ ) on your correspondent's report entitled "Lord Zuckerman Defends his Position" (Nature, 240, 247 ; 1972) and refers to what I said at the meeting of the British Association for Cancer Research.

I spoke about the development of the four new oncological centres, made a plea for closer integration of work being done in laboratories, in clinics and in the field and asked for greater emphasis on the flow of ideas from clinic to laboratory. I also asked some questions about accountability, effectiveness and efficiency, suggesting that in the context of the human cancer problem it was no less necessary and no more invidious to ask for assessment of the relevance and value of work done at subcellular level than it was at patient or community levels.

Dr Paul complains that in advocating greater emphasis on clinically oriented research, I was wrong in claiming that supracellular biologists had made a greater contribution to the welfare of the cancer patient than molecular biologists. The passage from my talk referred to was as follows:

"The mere asking of such controversial questions has been taken by some subcellular biologists to be a denial of the importance of their work, rather than an encouragement of the work of the supracellular biologists who have to date made a far greater contribution to the welfare of the cancer patient. 'Fundamental cancer research' has yet to match the long record of success of clinical and epidemiological investigations to which we owe so much in cancer prevention, detection and treatment. Hormone control of cancer arose from the observations of a surgeon, and both radiotherapy and chemotherapy had their origins in observations of their effects on man. Each clinical discovery has led to the creation of new research departments to fill important feedback functions. Successful preventive measures have stemmed in the case of mouth cancer from the work of the dental profession, and in lung cancer from that of the epidemiologists and statisticians. If cancer research is to advance more quickly toward practical control of the human disease processes involved, rather than make progress in some other if perhaps equally important function, then those engaged must have a close contact with the clinical scene and derive inspiration from it."

Of course it is Dr Paul who is wrong. His suggestion that cancer chemotherapy stemmed from molecular biology is quite untenable; it stemmed from clinical observation, its increasingly effective combinations developed from clinical practice and biochemistry was brought in later and most helpfully to support, to develop and to attempt to account for the success achieved.

Arguments about the merits of research at different biological levels are unprofitable since we need to understand the mechanisms of disordered growth at all levels of organization. I was discussing emphasis and relative effort. I am glad to see that Dr Paul, though regarding me as "puckish" when I am serious, also regards me as "reasonable" in holding the view that distinctions based on the value of work at different biological levels are pointless and that coordination of work at all levels is essential.

$$
\begin{aligned}
& \text { Yours faithfully, } \\
& \text { D. W. SMITHERs }
\end{aligned}
$$

The Royal Marsden Hospital,

London and Surrey,

Fulham Road,

London SW3 6JJ

\section{Acupuncture}

SiR,-There has been much recent interest in acupuncture, but as early as 1823 a treatise on the subject was published in England. In the December issue of The British Critic, 668 (1823), an unnamed reviewer discusses three new books. Each seeks to introduce a foreign method of medical treatment, and the only one which the reviewer feels is "deserving of serious consideration" is :

"Art XII. A Treatise on Acupuncturation; being a Description of a Surgical Operation originally peculiar to the Japanese and Chinese and by them denominated Zin-King, now introduced into European Practice, with Directions for its Performance, and Cases illustrating its Success. By James Morss Churchill, Member of the Royal College of Surgeons in London. 8 vo. 86 pp. 4s. Simpkin and Marshall. 1823."

Churchill's book receives the bulk of critical attention, while the other two, a treatise on Fumigating Baths (from France) and a treatise on Shampooing (from India), receive minimal attention as they are thought to be "of little worth".

In several long passages quoted from Churchill's book, the technique of acupuncture is described, and a whole range of maladies for which it had proved useful are mentioned. Churchill cites in particular two cases in which he himself had successfully performed acupuncture. The first was a woman suffering from rheumatic pain, the other was "William Morgan, a young man in the employment of a timber merchant". The latter had strained 